\title{
The Role of Photoprotection in Optimizing the Treatment of Atopic Dermatitis
}

\author{
Jaime Piquero-Casals (D) · José Manuel Carrascosa · Daniel Morgado-Carrasco • \\ Mridvika Narda · Carles Trullas · Corinne Granger · Gabriella Fabbrocini
}

Received: December 22, 2020 / Accepted: January 23, 2021 / Published online: February 13, 2021

(C) The Author(s) 2021

\begin{abstract}
Atopic dermatitis (AD) is a chronic inflammatory skin disease with an estimated prevalence of $10-15 \%$ in children and $2-10 \%$ in adults. Clinically, there is notable phenotypic variability driven by a complex interaction between genetics, immune function, and the environment. Impairment of the skin barrier plays a significant role in the pathogenesis of $\mathrm{AD}$. The apparent beneficial effect of sunlight in patients with atopic eczema is questioned due to its capacity to disrupt the skin barrier and generate
\end{abstract}

J. Piquero-Casals $(\bowtie)$

Dermik, Multidisciplinary Dermatology Clinic, Barcelona, Spain

e-mail: j.piquero@dermik.es

J. M. Carrascosa

Department of Dermatology, Hospital Universitari Germans Trias i Pujol, Universitat Autònoma of Barcelona, IGTP, Badalona, Spain

D. Morgado-Carrasco

Department of Dermatology, Hospital Clínic de Barcelona, Universitat de Barcelona, Barcelona, Spain

M. Narda · C. Trullas · C. Granger Innovation and Development, ISDIN, Barcelona, Spain

G. Fabbrocini

Department of Clinical Medicine and Surgery, University of Naples Federico II, Napoli, Italy free radicals that can damage proteins, lipids, and DNA. The sum of the external factors that an individual is exposed to throughout their lifetime is termed the exposome. Environmental factors such as sun exposure, temperature, and humidity contribute to both $\mathrm{AD}$ flares and regional prevalence variation. Literature on photoprotection in atopic dermatitis is very scarce. The use of adequate sunscreens in atopic dermatitis can ensure the level of photoprotection required to prevent skin photoaging and skin cancer and to mitigate skin barrier dysfunction, decrease inflammation, and neutralize facial redness. Herein we discuss and review the role of UV radiation and the exposome in the etiology of $\mathrm{AD}$, as well as the role of adequate photoprotection.

Keywords: Atopic dermatitis; Eczema; Exposome; Nonpharmacologic; Photoprotection; Skin barrier; Sunscreens; Ultraviolet radiation 


\section{Key Summary Points}

A topic dermatitis is a common inflammatory skin disease characterized by recurrent eczematous lesions and intense itch that can have an adverse effect on quality of life.

Key pathogenic mechanisms include a dysfunctional epidermal barrier and type 2-dominated cutaneous inflammation, which can be targeted by innovative biological and small-molecule therapies.

The diagnosis is made clinically, and management consists of education, the avoidance of triggers that can exacerbate the condition, skin care measures, and various treatment options.

Despite progress in the development of systemic drugs, topical treatments continue to be essential for both barrier function repair and the delivery of antiinflammatory molecules.

Natural factors such as ultraviolet radiation (UVR), temperature, and humidity also contribute to both $\mathrm{AD}$ flares and regional prevalence variation.

Exposure to solar ultraviolet radiation can reduce skin barrier function, and sunscreen use can help to protect against this UV-induced skin barrier impairment.

Sunscreen-containing moisturizers have dramatically improved photoprotection compliance. These products can provide moisturization by decreasing transepidermal water loss through the creation of an environment that is optimal for barrier repair.

\section{DIGITAL FEATURES}

This article is published with digital features, including a summary slide, to facilitate understanding of the article. To view digital features for this article go to https://doi.org/10. 6084/m9.figshare.13615931

\section{INTRODUCTION}

Atopic dermatitis (AD) is a multifocal disease with a complex pathogenesis. Different triggers are involved in $\mathrm{AD}$ within the context of atopic diathesis and hypersensitivity reactions of organs (including skin) that may be caused by causative factors (physical constitution) and the vulnerability of barrier function [1].

Exposure to solar radiation is today recognized to be a major causative factor of several dermatological pathologies that range from skin cancer and actinic keratosis, inflammatory dermatoses (including $\mathrm{AD}$ ), and photoaging. The use of topical sunscreens to prevent photoaging and skin cancer is an integral part of the strategy for reducing skin exposure to solar radiation, in combination with other methods such as using protective clothing and avoiding outdoor activities during hours corresponding to peak solar radiation [2]. Photoprotection in AD patients, however, serves dual objectives: ensuring an adequate level of sun protection and suppressing the exacerbation of signs and symptoms of $\mathrm{AD}$ that may be induced by solar exposure. Unfortunately, adverse skin reactions to sunscreens can be common in $\mathrm{AD}$ patients. Patients with $\mathrm{AD}$ may be at greater risk as they are exposed to a wide variety of potential allergens from these products. As such, the recommendation that sunscreens should be used requires special consideration for $\mathrm{AD}$ patients. Another critical aspect to consider is the itching symptomatology, which benefits from the use of ingredients with emollient and anti-inflammatory properties, as they can help to recover and maintain skin barrier function. To further complicate matters, while some reports suggest that sun exposure may worsen patient condition, these patients generally enjoy relief from symptoms in the summer months, suggesting that some sun exposure may be beneficial [3]. Therefore, the sunscreen recommendation for AD patients must consider this dichotomous relationship between $\mathrm{AD}$ and photoexposure. It 
is important to understand the unique needs of the $\mathrm{AD}$ patient when attempting to optimize photoprotection in this context.

The aim of this review is to discuss the factors that make the photoprotection needs of AD patients unique, and to provide recommendations regarding the characteristics of sunscreens for these patients. This article is based on previously conducted studies and does not contain any studies with human participants or animals performed by any of the authors. Patients gave their written consent for the publication of photographs.

\section{ULTRAVIOLET (UV) RADIATION AND SKIN BARRIER DYSFUNCTION}

The complex interplay among genetics, skin barrier deficiency, immunological derangement, and pruritus contributes to the development, progression, and chronicity of $\mathrm{AD}$. Abnormalities in filaggrin (FLG), other stratum corneum (SC) constituents, and tight junctions (TJs) induce and promote skin inflammation [4].

FLG is a key epidermal barrier protein required for the formation of the $\mathrm{SC}$, and is influenced by environmental factors such as climate, pollution, and the microbiome [5]. SC homeostasis relies greatly on FLG and its metabolic process. Epidermal barrier proteins also include transglutaminases, keratins, loricrin, intercellular proteins, and TJs. Together, all of these form a permeability barrier between adjacent cells and involve cell adhesion [6]. FLG is known to be decreased in the epidermis of $\mathrm{AD}$ patients [7], and null mutation of the FLG gene is the strongest risk factor for $\mathrm{AD}$. Due to the compromised barrier function, various allergens can easily penetrate into the skin and are more likely to induce contact dermatitis. The penetration of aeroallergens and irritating microorganisms into the dermis contribute to the Th2 immune response observed in lesions [8]. Type 2 cytokines inhibit the expression of structural cornified barrier proteins such as FLG, loricrin, involucrin, antimicrobial peptides (AMPs), and TJs.
Exposure to solar UV radiation can reduce skin barrier function because it can have dramatic effects on cell cohesion and mechanical integrity that are related to its effects on the intercellular components of the SC, including intercellular lipids and corneodesmosomes. Sunscreen use can help to protect against this UV-induced skin barrier impairment [9]. Emollient-rich moisturizers are the cornerstone of AD management because they improve barrier function, reduce xerosis, itch, and flares, and reduce the need for anti-inflammatory medication [10]. Sunscreens containing ingredients that have emollient properties and can protect and repair the skin barrier should be recommended in AD patients.

Sunlight can be a friend or foe to those living with $\mathrm{AD}$. The relationship between $\mathrm{AD}$ and photoexposure is marked by a peculiar dichotomy. The majority of $\mathrm{AD}$ patients benefit from UV radiation therapy and from exposure to the sun in a controlled natural setting [11, 12]. However, an estimated $10 \%$ of patients are reported to show photoaggravation [13]. At least two studies from Japan have reported patients with $\mathrm{AD}$ who suffer from recalcitrant facial erythema related to sun exposure $[14,15]$. Deguchi et al. [15] demonstrated that 41 (55\%) of $74 \mathrm{AD}$ patients with persistent facial erythema had experienced exacerbation of the facial lesions after sun exposure. In 28 of those 41 patients, the exacerbation lasted for more than $48 \mathrm{~h}$. This long-lasting response is considered to be true photoaggravation by UV radiation.

Photosensitivity in AD is a well-known but ill-defined phenomenon that seems to be more frequent in women, which should be kept in mind [16]. This can be difficult to recognize in clinical practice, as the symptoms may also be explained by other simultaneous exposures, such as humidity, heat, scratching, pollen exposure, or psychological factors. Also, some skincare products and comorbidities such as polymorphous light eruption could mask or worsen the sensitivity to UV radiation [17]. In a retrospective analysis of 17 patients with longstanding AD who suddenly developed photosensitivity to UVA, the onset of photosensitivity was reported during spring and summer and 
during exposure to artificial UVR as part of the patients' treatment regimen [13].

Although atopic dermatitis is widely known to be a dermatological condition, the systemic nature of the disease must not be ignored, as indicated by some of the comorbidities. Apart from allergic conditions, these comorbidities include an increased risk of cardiovascular disease, certain cancers, as well as a range of autoimmune and neuropsychiatric diseases [18]. Systemic immunosuppressive agents that are used to treat moderate to severe $\mathrm{AD}$, such as cyclosporine and azathioprine, increase photosensitivity and the risk of skin cancer [19].

Pityriasis alba (PA) is a localized hypopigmented disorder of childhood. It is a hallmark of eczema and probably the clinical expression of an impaired skin barrier in AD patients [20]. Although PA is very common in children and adolescents with $\mathrm{AD}$, the cause of $\mathrm{PA}$ is still unknown. As PA frequently involves facial skin, sun exposure may be considered one of the factors involved in the multifactorial mechanism of PA development. Hypopigmentation may be caused by inflammation and an inability to transfer melanosomes to surrounding keratinocytes. Treatment is often bypassed because of the self-resolving nature of the condition, the high cost of treatment options, and a slow response to therapy. Mild cleansers and sunscreens are recommended in $\mathrm{PA}$, though they will not clear PA lesions [21].

Elderly $\mathrm{AD}$ must be considered a separate clinical type of the disease because of its distinguishing manifestations that differ from the childhood manifestation. Apart from the appearance of lichenified eczema at the antecubital and popliteal fossa, AD can present in the elderly with atypical clinical phenotypes such as prurigo nodularis, nummular eczema, or generalized eczema more frequently than in other age groups. On the other hand, older patients often suffer from asteatosis and pruritus due to physiologic skin aging and comorbidities, for which they take medications that may worsen pruritus and dry skin [22].

Finally, some studies even suggest a reduced risk of malignant melanoma (MM) among $\mathrm{AD}$ patients [23], but they have an increased risk of other skin cancers as basal cell carcinoma (BCC) and squamous cell carcinoma (SCC) and require adequate photoprotection measures [24].

\section{Exposome and Skin Barrier Dysfunction}

The exposome is defined as the sum of all factors that have an effect on skin aging [25]. Exposomal factors can be categorized into nonspecific (human and natural factors affecting populations), specific (e.g., humidity, ultraviolet radiation, diet, pollution, allergens, water hardness), and internal (cutaneous and gut microbiota and host cell interactions) exposures.

$\mathrm{AD}$ is susceptible to aggravation by several intrinsic or environmental factors (Fig. 1). Flareups may be instigated by allergic or irritant type responses triggered by viral infections, food and environmental allergens, cosmetics (especially perfume), and weather, among other factors [26]. Some studies have reported contact sensitivity in patients with recalcitrant $\mathrm{AD}$ [27]. In a recent retrospective Spanish study, one-third of patients with therapy-resistant $\mathrm{AD}$ showed a benefit after positive patch testing and avoiding the substances that they were sensitized to [28].

Exacerbations of $\mathrm{AD}$ have been observed with greater concentrations of particulate (PM10, PM2.5) and gaseous $\left(\mathrm{NO}_{2}\right.$, volatile organic compounds, $\mathrm{O}_{3}, \mathrm{SO}_{2}$ ) air pollutants in several studies [29]. The mechanisms through which air pollution-induced health effects are mediated are poorly understood. As air pollution-induced health effects require the penetration of pollutants into the skin, skin barrier integrity is probably involved.

Additional lifestyle factors that impact $\mathrm{AD}$ are frequent detergent use, hard water, and diet [30, 31]. Sleep disturbance is frequently reported by $\mathrm{AD}$ patients. The impact of the itch-scratch cycle and secondary effects of inflammatory cytokines on sleep regulation have been described in these individuals [32].

\section{SUNLIGHT AND PHOTOTHERAPY}

Controlled sun exposure has several benefits for $\mathrm{AD}$ patients. In addition to affecting the epidermal barrier, UV exposure also modifies the 


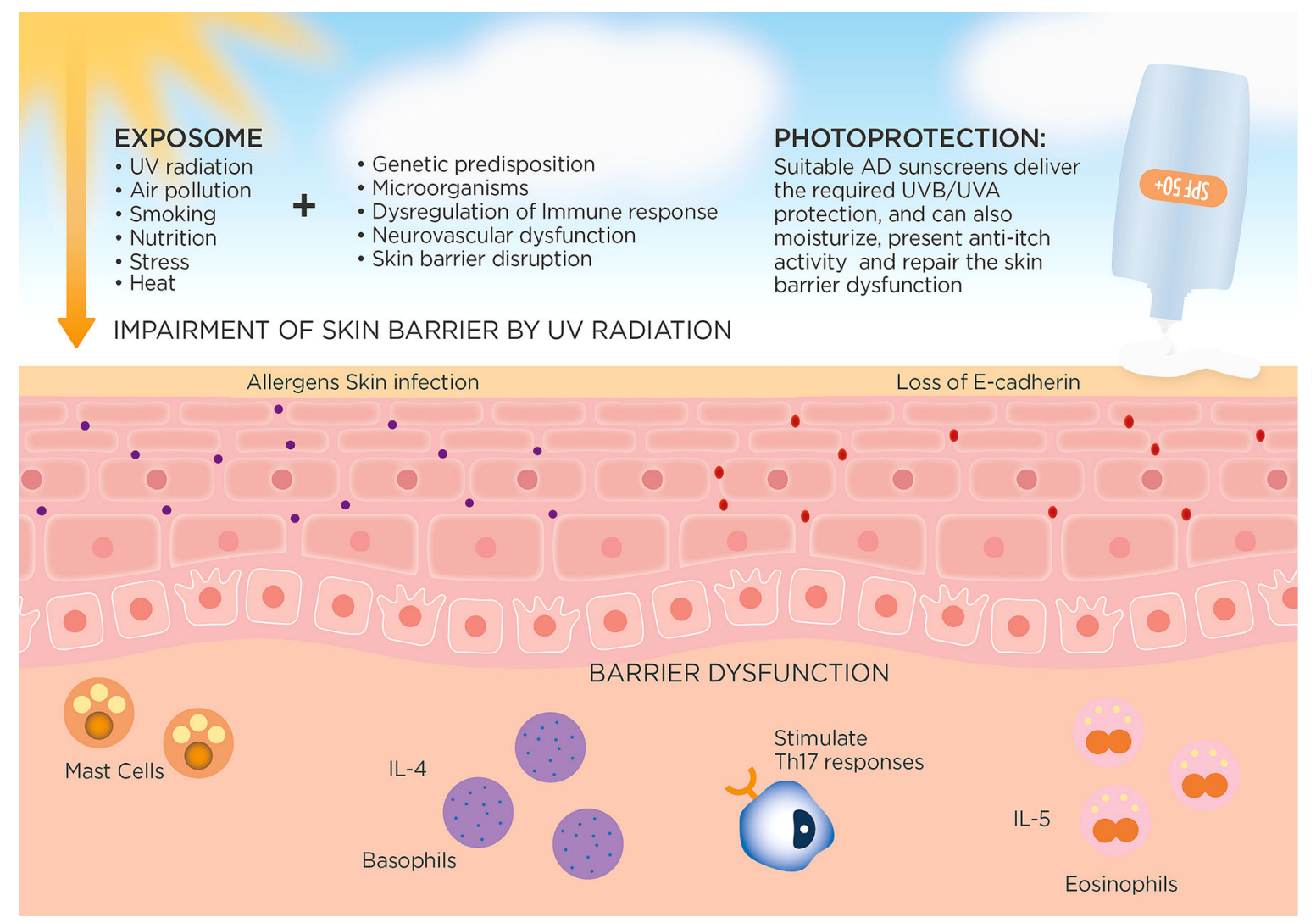

Fig. 1 Solar UV radiation and other exposome factors in AD

immune reaction. The effect on the immune system can either be primarily a local effect on the cutaneous immune system and/or it can extend to the systemic immune response. Due to its profound effects on exposed cells and on local and systemic immune systems, UV can be used quite effectively in skin phototherapy for $\mathrm{AD}$ patients [33].

UV radiation may also increase the thickness of the stratum corneum though a phenomenon called photohardening [34], and reduce the colonization of Staphylococcus aureus in the skin, thus preventing the well-known superantigenlinked exacerbations of AD [35]. Several studies have suggested that higher temperatures and lower latitudes may be associated with a lower prevalence of $\mathrm{AD}$ [36-38]. Also, sun exposure can improve the mood, which is essential for AD patients who suffer from this chronic disease that can limit their daily activities. On the other hand, the long-term cumulative damage of solar radiation includes photoaging and skin carcinogenesis. The use of artificial lamps that emit narrow-band UVB at $311 \mathrm{~nm}$ (NB-UVB) is recommended in AD. Medium-dose ultraviolet A 340-400 nm (UVA1) appears to be as effective as NB-UVB but is more time-consuming [39]. Phototherapy using UVA1 and NB-UVB could be prescribed for selected $\mathrm{AD}$ patients. The results from a recent study (Pacifico et al. [40]) in adult patients with severe $\mathrm{AD}$ emphasize that UVA1 phototherapy should be considered among the first approaches in the treatment of patients with severe generalized $\mathrm{AD}$. This study also demonstrated that in darker-skinned patients, a high dose of UVA1 is more effective than a medium dose of UVA1. NB-UVB appears to be similarly effective to medium-dose UVA1 but is less time-consuming. On the other hand, a UVB excimer laser and excimer lamp might be the best options for clearing localized therapyresistant lesions [40]. 


\section{AD AND VITAMIN D}

Solar radiation exposure of the skin is the main source of vitamin D. Low levels of vitamin D, especially vitamin D3, have been linked to dermatological disorders, including AD [41, 42]. Furthermore, vitamin D supplementation may provide a modest benefit in $\mathrm{AD}$, particularly during winter disease flares [43]. As such, it may appear that the regular use of sunscreen may be counterproductive for vitamin D levels. However, a cross-sectional, nationally representative survey of 5920 adults aged 18-60 years in the US showed that frequent sunscreen did not decrease vitamin D levels [44]. Sunscreens do not completely block the cutaneous absorption of UVR; a minor fraction of UVB radiation penetrates the skin, even through high-SPF sunscreens [45].

\section{SUNSCREENS AND CONTACT DERMATITIS}

Patients with AD present skin barrier dysfunction and increased penetration of allergens, they frequently use emollients and topical medications, and they may be predisposed to developing allergic contact dermatitis (ACD) [46]. ACD is an important comorbidity and can exacerbate AD.

Contact dematitis or phototoxic and photoallergic cutaneous reactions to topical sunscreens are rare in the general population and can be due to UV filters, fragrances, preservatives, or other ingredients. Repeated exposure to UV filters due to their presence in nonsunscreen cosmetic products possibly facilitates sensitization and may explain why some patients react to chemically unrelated UV filters [47]. Since allergic/photoallergic reactions to sunscreens may be less rare in $\mathrm{AD}$ patients, adverse reactions to sunscreens should be minimized. For this reason, is important for dermatologists to be aware of reactions to active UV filters [48], and a photopatch test should always be performed in the case of suspected contact sensitivity to these products [49]. Among chemical filters, benzophenone-3 (oxybenzone) is the leading allergen and photoallergen [48].
Although avobenzone and octocrylene are involved in allergic and photoallergic contact dermatitis (PACD) reactions [50], the available data show that they are rare sensitizers and may be considered safe [51]. Octocrylene is a photostable UVB and UVAII absorber that photostabilizes avobenzone and works with other UV filters to deliver broad photoprotection.

\section{SUNSCREENS FOR AD PATIENTS}

People affected by AD can be especially vulnerable to UV light and can find it more of a challenge to find sunscreen products that work for their skin. Sunscreen-containing moisturizers have dramatically improved photoprotection compliance. These products can provide moisturization by decreasing transepidermal water loss (TEWL) through the creation of an environment that is optimal for barrier repair.

\section{The Vehicle in AD Sunscreens}

Using an appropriate combination of ingredients in a sunscreen formula has the potential to mitigate barrier dysfunction in $\mathrm{AD}$ patients (Table 1). The use of occlusive agents such as dimethicone and petrolatum as well as humectants such as glycerin and hyaluronic acid can help to restore the corneocyte and intercellular lipid organization [52]. Topical dexpanthenol acts like a moisturizer, improving stratum corneum hydration, stimulating epithelialization, reducing TEWL, and maintaining skin softness and elasticity [53]. Dexpanthenol also mitigates the itching. Another ingredient is bisabolol, an active plant extract that is isolated from German chamomile and thought to have anti-irritant, anti-inflammatory, and skin-soothing properties [54].

Two other functional ingredients used in sunscreen vehicles that are suitable for skin with atopic dermatitis are alpha-tocopherol and ectoine. Topical application of alpha-tocopherol, the most prominent naturally occurring form of vitamin $\mathrm{E}$, inhibited UVB-induced photocarcinogenesis and DNA photodamage in $\mathrm{C} 3 \mathrm{H}$ mice in vivo [55]. On the other hand, 
Table 1 Criteria for sunscreens suitable for skin with atopic dermatitis

\section{Criteria for sunscreens suitable for skin with atopic dermatitis}

Avoids patient-specific $\mathrm{AD}$ triggers

Mineral-based sunscreen ingredients: titanium dioxide $\left(\mathrm{TiO}_{2}\right)$ and zinc oxide $(\mathrm{ZnO})$ or a combination of chemical and inorganic filters

Improved sensory attributes for better compliance

SPF 30 or greater

Provides broad-spectrum protection from both UVB and UVA rays

Lightweight texture that protects and repairs an impaired skin barrier

Water resistant

Noncomedogenic and formulated to minimize skin allergies (hypoallergenic)

Contains functional vehicle ingredients such as dexpanthenol, ectoine, vitamin E, bisabolol

Table 2 Summary of useful nonfilter ingredients in sunscreens for AD patients

\begin{tabular}{|c|c|}
\hline Ingredient & Property \\
\hline Dexpanthenol & $\begin{array}{l}\text { Moisturizer; improves stratum corneum hydration, reduces transepidermal water loss, maintains } \\
\text { skin softness and elasticity, and mitigates itch }\end{array}$ \\
\hline $\begin{array}{l}\text { Vitamin E (alpha- } \\
\text { tocopherol) }\end{array}$ & Antioxidant; inhibits UVB-induced photocarcinogenesis and DNA photodamage \\
\hline Ectoine & $\begin{array}{l}\text { Water-binding properties; topical application was shown to improve skin hydration and barrier } \\
\text { function in AD subjects }\end{array}$ \\
\hline Bisabolol & Anti-irritant, anti-inflammatory, and antimicrobial properties; relieves pruritus \\
\hline
\end{tabular}

ectoine is a low-molecular tetrahydropyrimidine ingredient with water-binding properties. Topical application was shown to improve skin hydration and barrier function in mild to moderate AD [56] (Table 2).

\section{Prescribing a Sunscreen for a Specific Patient with AD}

When a physician prescribes a topical drug or cosmetic for the treatment/management of $\mathrm{AD}$, he or she takes into consideration the age of the patient, the affected area, and the activity phase of the eczema. The same holds true for sunscreens. In the acute phase, the lesional skin is red and inflamed, hypersensitive, and warm. Light, refreshing $\mathrm{O} / \mathrm{W}$ emulsions that allow perspiration may therefore be appropriate during this phase. Moisturizing sprays can also be comfortable and easy-to-use options. Regarding the age of the patient, children benefit from $\mathrm{W} / \mathrm{O}$ vehicles and physical filters, whereas adolescents need noncomedogenic products and sometimes tinted sunscreens for camouflage. It is important to note that unctuous creams can have an occlusive effect and generate miliaria or acneiform eruptions. When chronic eczema (hyperpigmented and thickened lichenified plaques) affects nonfacial areas, it is very important to provide hydration and $\mathrm{W} / \mathrm{O}$ sunscreens. The physical activity of the patient is 
also very important. When performing outdoor sports such as running or tennis, water-resistant sunscreens or even products that can be applied to wet skin are needed. Furthermore, they should be safe in the event of accidental contact with the eyes.

\section{Choosing UV Filters for AD Sunscreens}

UV filters are the active ingredients of sunscreen products, and can be classified into organic (chemical) and inorganic UV filters. Organic filters can absorb UVB, UVA, or both radiations through their aromatic moieties, while inorganic filters attenuate UVB/UVA mainly by absorption, along with some scattering. UV filters are regulated globally as either cosmetics, quasi-drugs, or over-the-counter (OTC) drugs. Prior to their approval, UV filters are subjected to a stringent level of testing to detect possible safety issues. Despite this, the safety of sun filters has been challenged on the basis that they may cause contact and photocontact allergies, may be endocrine disruptors, or may penetrate the skin, resulting in systemic exposure. Before recommending a sunscreen product for a subject with $\mathrm{AD}$, the patient should be asked about previous irritant or ACD and/or photoallergic/ phototoxic cutaneous reactions. It is important to recommend a broad-spectrum sunscreen that has been developed to minimize the incidence of skin allergies, and to instruct the patient to apply a small amount of the sunscreen on the inside of the forearm for a few days to check if there is a skin reaction. If the $\mathrm{AD}$ subject does not have a prior history of intolerance to chemical filters, a broad-spectrum sunscreen that has an SPF of 30 or higher and is based on chemical filters or on a combination of chemical and inorganic filters should be recommended. These types of sunscreens have better sensory attributes and consumer compliance than sunscreens based only on inorganic filters. For AD subjects with a history of ACD or photoallergic/phototoxic cutaneous reactions induced by chemical sun filters, a broad-spectrum sunscreen with an SPF of 30 or higher that is based exclusively on physical (inorganic) filters is best. The UV action spectrum of the inorganic particulate filters (zinc oxide and titanium dioxide) is UVB/UVA, and these UV filters show low rates of sensitization and low allergenic potential. The first generation of these inorganic UV filters yielded an unsatisfactory whitened appearance when they were applied to the skin due to their large particle size and high refractive index. However, the micronized versions of these particles, nano zinc oxide and nano titanium dioxide, are almost completely transparent and as such more cosmetically appealing. Although concerns have been raised about the ability of these metal oxide nanoparticles to penetrate into the skin and generate reactive oxygen species, published studies suggest that the microsized and nanosized $\mathrm{ZnO}$ and $\mathrm{TiO}_{2}$ particles used in sunscreen products do not penetrate into the skin, they are not toxic, irritating, sensitizing, or photosensitizing, and they do not pose a risk to humans [57].

The use of a combination of liposoluble and water-soluble UV filters may allow the total amount of UV filters needed to achieve broadspectrum sun protection to be reduced, which could decrease adverse skin reactions and the impact of the sunscreen on the marine environment.

\section{CONCLUSION}

$\mathrm{AD}$ is a chronic and highly prevalent skin disorder [58] that can seriously degrade quality of life. UV radiation plays an important role in the pathogenesis of $\mathrm{AD}$ and can aggravate this disorder. Appropriate skin care, including the regular use of moisturizers, is the cornerstone of therapy for AD. Due to the propensity of $\mathrm{AD}$ patients to suffer from dryness, pruritus, and impairment of the skin barrier, broad-spectrum sunscreens for AD patients should ideally contain ingredients that have emollient/moisturizing properties and can repair the skin barrier. These adequately formulated sunscreens will deliver the required UVB/UVA protection while also moisturizing the skin, repairing skin barrier dysfunction, relieving itch, and possibly reducing inflammation and providing camouflage. 


\section{ACKNOWLEDGEMENTS}

Funding. The journal's Rapid Service Fee was supported by ISDIN.

Authorship. All named authors meet the International Committee of Medical Journal Editors (ICMJE) criteria for authorship for this article, take responsibility for the integrity of the work as a whole, and have given their approval for this version to be published.

Disclosures. Jaime Piquero-Casals, José Manuel Carrascosa, Daniel Morgado-Carrasco and Gabriella Fabbrocini served as a consultant to ISDIN. Mridvika Narda, Corinne Granger, and Carles Trullas are employed by ISDIN.

Compliance With Ethics Guidelines. This article is based on previously conducted studies and does not contain any studies with human participants or animals performed by any of the authors. Patients gave written consent for publication of photographs.

Data Availability. Data sharing is not applicable to this article as no datasets were generated or analyzed during the current study.

Open Access. This article is licensed under a Creative Commons Attribution-NonCommercial 4.0 International License, which permits any non-commercial use, sharing, adaptation, distribution and reproduction in any medium or format, as long as you give appropriate credit to the original author(s) and the source, provide a link to the Creative Commons licence, and indicate if changes were made. The images or other third party material in this article are included in the article's Creative Commons licence, unless indicated otherwise in a credit line to the material. If material is not included in the article's Creative Commons licence and your intended use is not permitted by statutory regulation or exceeds the permitted use, you will need to obtain permission directly from the copyright holder. To view a copy of this licence, visit http://creativecommons.org/licenses/by$\mathrm{nc} / 4.0 /$.

\section{REFERENCES}

1. Munera-Campos M, Carrascosa JM. Innovation in atopic dermatitis: from pathogenesis to treatment. Actas Dermosifiliogr. 2020;111(3):205-21.

2. Krutmann J, Passeron T, Gilaberte $Y$, Granger C, Leone G, Narda M, Schalka S, Trullas C, Masson P, Lim HW. Photoprotection of the future: challenges and opportunities. J Eur Acad Dermatol Venereol. 2020;34(3):447-54.

3. Napolitano M, Monfrecola G, Fabbrocini G, Fattore D, Patrí A, Patruno C. Impact of sun exposure on adult patients affected by atopic dermatitis. G Ital Dermatol Venereol. 2020;17.

4. Rerknimitr P, Otsuka A, Nakashima C, Kabashima $\mathrm{K}$. The etiopathogenesis of atopic dermatitis: barrier disruption, immunological derangement, and pruritus. Inflamm Regen. 2017;5(37):14.

5. Ahn K, Kim BE, Kim J, Leung DY. Recent advances in atopic dermatitis. Curr Opin Immunol. 2020;13(66):14-21.

6. Kim BE, Leung DYM. Significance of skin barrier dysfunction in atopic dermatitis. Allergy Asthma Immunol Res. 2018;10(3):207-15.

7. Palmer $\mathrm{CN}$, Irvine $\mathrm{AD}$, Terron-Kwiatkowski A, Zhao $\mathrm{Y}$, Liao H, Lee SP, et al. Common loss-of-function variants of the epidermal barrier protein filaggrin are a major predisposing factor for atopic dermatitis. Nat Genet. 2006;38:441-6.

8. Agrawal R, Woodfolk JA. Skin barrier defects in atopic dermatitis. Curr Allergy Asthma Rep. 2014;14(5):433. https://doi.org/10.1007/s11882014-0433-9.

9. Berkey C, Biniek K, Dauskardt RH. Screening sunscreens: protecting the biomechanical barrier function of skin from solar ultraviolet radiation damage. Int J Cosmet Sci. 2017;39(3):269-74.

10. Langan SM, Irvine AD, Weidinger S. Atopic dermatitis. Lancet. 2020;396(10247):345-60.

11. Patrizi A, Savoia F, Giacomini F, Tabanelli M, Gurioli C. The effect of summer holidays and sun exposure on atopic dermatitis. G Ital Dermatol Venereol. 2009;144(4):463-6.

12. Kemp AS, Ponsonby AL, Pezic A, Cochrane JA, Dwyer T, Jones $G$. The influence of sun exposure in childhood and adolescence on atopic disease at adolescence. Pediatr Allergy Immunol. 2013;24(5): 493-500. 
13. Ellenbogen E, Wesselmann U, Hofmann SC, Lehmann P. Photosensitive atopic dermatitis-a neglected subset: clinical, laboratory, histological and photobiological workup. J Eur Acad Dermatol Venereol. 2016;30(2):270-5.

14. Omoto M, Sugiura H, Uehara M. Histopathological features of recalcitrant erythema of the face in adult patients with atopic dermatitis. J Dermatol. 1994;21:87-91.

15. Deguchi H, Danno K, Sugiura H, Uehara M. Sun exposure is an aggravating factor responsible for the recalcitrant facial erythema in adult patients with atopic dermatitis. Dermatology. 2002;204(1):23-8.

16. Ten Berge O, van Weelden H, Bruijnzeel-Koomen CA, de Bruin-Weller MS, Sigurdsson V. Throwing a light on photosensitivity in atopic dermatitis: a retrospective study. Am J Clin Dermatol. 2009;10(2):119-23.

17. Rutt VL, Reed KX, Liu X, Richard EG, Purcell SM. Photosensitive atopic dermatitis exacerbated by UVB exposure. Cutis. 2017;100(3):180-4.

18. Brunner PM, Silverberg JI, Guttman-Yassky E, Paller AS, Kabashima K, Amagai M, Taieb A. Increasing comorbidities suggest that atopic dermatitis is a systemic disorder. J Invest Dermatol. 2017;137(1): 18-25.

19. Andersen YMF, Egeberg A, Skov L, Thyssen JP. Comorbidities of atopic dermatitis: beyond rhinitis and asthma. Curr Dermatol Rep. 2017;6(1):35-41.

20. Jadotte YT, Janniger CK. Pityriasis alba revisited: perspectives on an enigmatic disorder of childhood. Cutis. 2011;87(2):66-72.

21. Fenner J, Silverberg NB. Skin diseases associated with atopic dermatitis. Clin Dermatol. 2018;36(5): 631-40.

22. Patruno C, Napolitano M, Argenziano G, et al. Dupilumab therapy of atopic dermatitis of the elderly: a multi-centre, real-life study. J Eur Acad Dermatol Venereol. 2020. https://doi.org/10.1111/ jdv.17094 (Epub ahead of print. PMID: 33332697).

23. Synnerstad I, Fredrikson M, Ternesten-Bratel A, et al. Low risk of melanoma in patients with atopic dermatitis. J Eur Acad Dermatol Venereol. 2008;22(12):1423-8.

24. Jensen AO, Svaerke C, Körmendiné Farkas D, Olesen AB, Kragballe K, Sørensen HT. Atopic dermatitis and risk of skin cancer: a Danish nationwide cohort study (1977-2006). Am J Clin Dermatol. 2012;13(1):29-36.
25. Krutmann J, Bouloc A, Sore G, Bernard BA, Passeron $\mathrm{T}$. The skin aging exposome. J Dermatol Sci. 2017;85(3):152-61.

26. Silverberg NB. A practical overview of pediatric atopic dermatitis, part 2: triggers and grading. Cutis. 2016;97(5):326-9.

27. Tamagawa-Mineoka $\mathrm{R}$, Masuda $\mathrm{K}$, Ueda $\mathrm{S}$, et al. Contact sensitivity in patients with recalcitrant atopic dermatitis. J Dermatol. 2015;42:720-2.

28. López-Jiménez EC, Marrero-Alemán G, Borrego L. One-third of patients with therapy-resistant atopic dermatitis may benefit after patch testing. J Eur Acad Dermatol Venereol. 2019;33(10):e377-8.

29. Hassoun Y, James C, Bernstein DI. The effects of air pollution on the development of atopic disease. Clin Rev Allergy Immunol. 2019;57(3):403-14.

30. Danby SG, Brown K, Wigley AM, Chittock J, Pyae PK, Flohr C, Cork MJ. The effect of water hardness on surfactant deposition after washing and subsequent skin irritation in atopic dermatitis patients and healthy control subjects. J Invest Dermatol. 2018;138(1):68-77.

31. Passeron T, Krutmann J, Andersen ML, Katta R, Zouboulis CC. Clinical and biological impact of the exposome on the skin. J Eur Acad Dermatol Venereol. 2020;34(Suppl 4):4-25.

32. Li JC, Fishbein A, Singam V, et al. Sleep disturbance and sleep-related impairment in adults with atopic dermatitis: a cross-sectional study. Dermatitis. 2018;29:270-7.

33. Rodenbeck DL, Silverberg JI, Silverberg NB. Phototherapy for atopic dermatitis. Clin Dermatol. 2016;34(5):607-13.

34. Jekler J, Larko O. Combined UVA-UVB vs. UVB phototherapy for atopic dermatitis: a paired-comparison study. J Am Acad Dermatol. 1990;22:49-53.

35. Faergemann J, Larko O. The effect of UV-light on human skin microorganisms. Acta Derm Venereol. 1987;67:69-72.

36. Silverberg JI, Hanifin J, Simpson EL. Climatic factors are associated with childhood eczema prevalence in the United States. J Invest Dermatol. 2013;133: 1752-9.

37. Fuertes E, Flohr C, Silverberg JI, Standl M, Strachan DP, ISAAC Phase Three Study Group. Global associations between UVR exposure and current eczema prevalence in children from ISAAC phase three. J Invest Dermatol. 2017;137(6):1248-56. 
38. Kantor R, Silverberg JI. Environmental risk factors and their role in the management of atopic dermatitis. Expert Rev Clin Immunol. 2017;13(1): 15-26.

39. Gambichler T, Othlinghaus N, Tomi NS, HollandLetz T, Boms S, Skrygan M, Altmeyer P, Kreuter A. Medium-dose ultraviolet (UV) A1 vs. narrowband UVB phototherapy in atopic eczema: a randomized crossover study. Br J Dermatol. 2009;160(3):652-8.

40. Pacifico A, Iacovelli P, Damiani G, Ferraro C, Cazzaniga S, Conic RRZ, Leone G, Morrone A. "High dose" vs. "medium dose" UVA1 phototherapy in Italian patients with severe atopic dermatitis. J Eur Acad Dermatol Venereol. 2019;33(4):718-24.

41. Kechichian E, Ezzedine K. Vitamin D and the skin: an update for dermatologists. Am J Clin Dermatol. $2018 ; 19(2): 223-35$.

42. Wei J, Jaleel T, MacLeod AS, Ji JS. Inverted U-shaped relationship between vitamin $\mathrm{D}$ and ever-reported eczema in US adults. Allergy. 2019;74(5):964-75.

43. Sidbury R, Tom WL, Bergman JN, et al. Guidelines of care for the management of atopic dermatitis: section 4. Prevention of disease flares and use of adjunctive therapies and approaches. J Am Acad Dermatol. 2014;71:1218-33.

44. Linos E, Keiser E, Kanzler M, Sainani KL, Lee W, Vittinghoff E, Chren MM, Tang JY. Sun protective behaviors and vitamin D levels in the US population: NHANES 2003-2006. Cancer Causes Control. 2012;23(1):133-40.

45. Kannan S, Lim HW. Photoprotection and vitamin D: a review. Photodermatol Photoimmunol Photomed. 2014;30:137-45.

46. Napolitano M, Fabbrocini G, Patruno C. Allergic contact dermatitis in patients with atopic dermatitis: a retrospective study. J Allergy Clin Immunol Pract. 2019;7(7):2459-61.

47. Uter W, Gonçalo M, Yazar K, Kratz EM, Mildau G, Lidén C. Coupled exposure to ingredients of cosmetic products: III. Ultraviolet filters. Contact Dermatitis. 2014;71(3):162-9.

48. Heurung AR, Raju SI, Warshaw EM. Adverse reactions to sunscreen agents: epidemiology, responsible irritants and allergens, clinical characteristics, and management. Dermatitis. 2014;25:289-326.
49. Jansen R, Osterwalder U, Wang SQ, et al. Photoprotection part II. Sunscreen: development, efficacy, and controversies. J Am Acad Dermatol. 2013;69(6):867.e1-14.

50. Avenel-Audran M, Dutartre H, Goossens A, et al. Octocrylene, an emerging photoallergen. Arch Dermatol. 2010;146:753-7.

51. Berardesca E, Zuberbier T, Sanchez Viera M, Marinovich M. Review of the safety of octocrylene used as an ultraviolet filter in cosmetics. J Eur Acad Dermatol Venereol. 2019;33(Suppl 7):25-33.

52. Draelos ZD. The multifunctional value of sunscreen-containing cosmetics. Skin Ther Lett. 2011;16(7):1-3.

53. Ebner F, Heller A, Rippke F, et al. Topical use of dexpanthenol in skin disorders. Am J Clin Dermatol. 2002;3:427-33.

54. Arenberger $\mathrm{P}$, Arenbergerová $\mathrm{M}$, Drozenová $\mathrm{H}$, Hladíková M, Holcová S. Effect of topical heparin and levomenol on atopic dermatitis: a randomized four-arm, placebo-controlled, double-blind clinical study. J Eur Acad Dermatol Venereol. 2011;25(6): 688-94.

55. McVean M, Liebler DC. Prevention of DNA photodamage by vitamin $\mathrm{E}$ compounds and sunscreens: roles of ultraviolet absorbance and cellular uptake. Mol Carcinog. 1999;24(3):169-76.

56. Marini A, Reinelt K, Krutmann J, Bilstein A. Ectoinecontaining cream in the treatment of mild to moderate atopic dermatitis: a randomized, comparator-controlled, intra-individual double-blind, multi-center trial. Skin Pharmacol Physiol. 2014;27(2):57-65.

57. Osmond-McLeod MJ, Oytam Y, Kirby JK, GomezFernandez L, Baxter B, McCall MJ. Dermal absorption and short-term biological impact in hairless mice from sunscreens containing zinc oxide nanoor larger particles. Nanotoxicology. 2014;8(Suppl 1):72-84.

58. Laughter MR, Maymone MBC, Karimkhani C, et al. The burden of skin and subcutaneous diseases in the United States from 1990 to 2017. JAMA Dermatol. 2020;156(8):874-81. 